\title{
CFD ANALYSIS OF THE NEEDLE TIP ANGLE IN PELTON INJECTOR ON JET QUALITY FOR THE POWER GENERATION
}

\author{
Daniel G. Taborda \\ Department of Mechatronics Engineering ${ }^{l}$ \\ danielgiraldo209012@correo.itm.edu.co \\ Jorge Sierra-Del Rio \\ Department of Mechatronics Engineering ${ }^{l}$ \\ jorgesierra@itm.edu.co \\ Juan Diego Perez-Alvarez. \\ Department of Mechatronics Engineering ${ }^{l}$ \\ juanperez238421@correo.itm.edu.co \\ Arley Cardona-Vargas \\ Department of Mechatronics Engineering ${ }^{l}$ \\ arleycardona5670@correo.itm.edu.co \\ Daniel Sanin Villa \\ Department of Mechanic Engineering \\ Pontifical Bolivarian University \\ Cq. 1 \#70-01, Medellin, Antioquia, Colombia, 54 \\ daniel.sanin@upb.edu.co \\ ${ }^{1}$ Metropolitan Technological Institute \\ Cl. 75 \#75-101, Medellin, Antioquia, Colombia, 54
}

\begin{abstract}
Fossil fuels are energy sources that supply a large part of the world's energy generation. However, they produce greenhouse gases such as carbon dioxide $\left(\mathrm{CO}_{2}\right)$, nitrogen oxide $\left(\mathrm{NO}_{\mathrm{x}}\right)$ and particulates that increase global warming. For this reason, other forms of renewable energy such as hydropower have begun to be implemented through turbomachinery such as Pelton turbines, which significantly reduce these emissions since they are highly efficient turbines based on the use of natural resources (water). Pelton turbines are based mainly on three components for their operation, which are the Pelton injector, the bucket and the wheel. The injector is an important component in the energy transformation of Pelton turbines. Although to analyze its behavior, it is possible to use fluid dynamics (CFD) software to predict the trajectory of the flow through a solid or free surface. The objective of this work is to analyze by means of computational fluid dynamics (CFD) the incidence of the length and the needle tip angle of a Pelton turbine injector on the generated power. For this, an ANSYS 2020R2 computational fluid analysis software was used to study how the variation of the injector needle tip angle influences through the volume of fluid (VOF) method, starting from the generation of a commercial model with a tip angle of $60^{\circ}$ and two (2) geometries of $55^{\circ}$ and $75^{\circ}$ respectively. Numerical results show a better performance for the $75^{\circ}$ angle of $96 \%$ and lower for the $55^{\circ}$ and $60^{\circ}$ with $94.1 \%$ and $95.5 \%$ respectively, whereby steeper angles achieve higher performances. In summary, the present study pretends to increase the power generation, in the face of phenomena occurred in the energy transfer. Although the performance of the injector in each angle configuration must be tested in practice.
\end{abstract}

Keywords: computational fluids dynamics, volume of fluid method, injector efficiency.

DOI: $10.21303 / 2461-4262.2021 .001828$

\section{Introduction}

Nowadays, fossil fuels supply $84.3 \%$ of the world's total electricity generation. However, the combustion and generation of pollutants emitted into the atmosphere such as carbon dioxide $\left(\mathrm{CO}_{2}\right)$ and nitrogen oxides $\left(\mathrm{NO}_{\mathrm{x}}\right)$ increase the production of greenhouse gases (GHG) and, consequently, global warming. For this reason, the use of hydropower has been increasing in recent years as a renewable energy source, where it is estimated that today they cover approximately $6 \%$ of the 
world's total electricity generation [1]. Here, hydraulic impulse turbines such as Pelton turbines have become one of the most used renewable energy sources since their invention by [2] in 1880, due to they take advantage of the kinetic energy and potential of high head and relatively low flow rates from an injector that is responsible for accelerating and regulating the flow of water towards the turbine buckets, transforming the kinetic energy into rotational mechanical energy [3].

The main factors affecting the performance of Pelton turbines are found in the casing, the injector, the runner and the operating conditions. Among them, the injector plays an important role in the conversion of fluid pressure energy into kinetic energy. For this reason, in recent years, Pelton turbine efficiency gains have been studied with the support of experimental and/or numerical methodologies, modifying both geometrical and operational parameters in order to estimate the effects of the injector on energy transfer. However, the analysis of Pelton-type turbines is complex and requires sophisticated equipment implementing computational techniques such as the VOF (volume of fluid) method [4] and the SPH (Smoothed Particle Hydrodynamics) [5] or experimental observation and measurement techniques of water flow such as the LDA (Laser Doppler Anemometry) method [6,7] and PIV (Particle Image Velocity) devices [8]. For example, [9, 10] adopted the VOF model configurations to analyze the jet characteristics in the face of head changes. The results of their investigation revealed that the secondary flows induced by Dean vortices upstream of the injector caused deformations downstream of the injector affecting the turbine performance. Then, [11] numerically and experimentally analyzed the free jet surface of a Pelton turbine, and confirmed that the asymmetric presence in the jet profile is due to the secondary flows influenced by the Dean vortices generated at the bend of the elbow. Later, [12-14], compared the effects on jet quality in industrial Pelton turbines by flow visualization and performance tests, confirming that jet dispersion is the principal cause of the decrease in Pelton turbine performance. Then, [15-17] analyze by numerical studies the effect of jet quality on the efficiency of a Pelton turbine injector for three configurations of $80 / 55,110 / 70$ and 180/90 in nozzle angle and needle tip angle respectively, finding efficiencies close to $98 \%$ at steeper needle tip angles. [18-21] analyzed the jet flow from the injector opening percentage, showing increases in efficiencies close to $4 \%$ for openings between $60 \%$ and $90 \%$. Then, [22, 23] numerically compared turbine injector performance under varying needle and nozzle angles, concluding better efficiencies at steeper angles. Finally, [24, 25] compared the changes in turbine performance with changing geometrical parameters in the injector, confirming that the cause of jet dispersion is mainly due to the injector geometry.

In general, it is possible to improve efficiency by varying the geometrical parameters and percentage of a Pelton turbine injector, especially the length and the needle tip angle. However, improving efficiency involves analyzing factors that affect the quality of the jets, whether in dispersion, deformation or rotation. Although nowadays there are numerous studies to guarantee an injector with optimum characteristics, there is still a lack of studies to further increase the turbine efficiency. For this reason, this study focuses only on the CFD analysis of the variation in the needle tip angle using VOF simulation methods. Thus, the objective of the study is to analyze by CFD simulation the incidence of the length and the needle tip angle of a Pelton turbine injector on the generated power.

\section{Methodology}

\section{1. Geometric generation}

This work was developed for two injectors with needle tip angle of $55^{\circ} / 130^{\circ}$ and $75^{\circ} / 130^{\circ}$, starting from the model provided by the Techydro trademark, which considers a needle tip angle of $60^{\circ} / 130^{\circ}$. The geometrical parameters in the design of the injector were obtained through the methodology established in Fig. 1 where the site conditions were initially determined, specifically the head (1), the generated power (2) and the velocity of the jet (3). Then, the jet diameter $\left(d_{0}\right)$ was determined by (4) and the nozzle diameter $\left(d_{1}\right)$ by (5) from the site conditions corresponding to the flow and head of $0.021 \mathrm{~m}^{3} / \mathrm{s}$ and $35 \mathrm{~m}$ respectively. Finally, it was validated by (6) if the calculated nozzle diameter is between the maximum and minimum nozzle diameter allowed.

Once the diameter of the nozzle was determined and using the parameters established in Table 1 and Fig. 2 according to the study carried out by [26], the dimensions corresponding to the geometry of the injector were determined. 


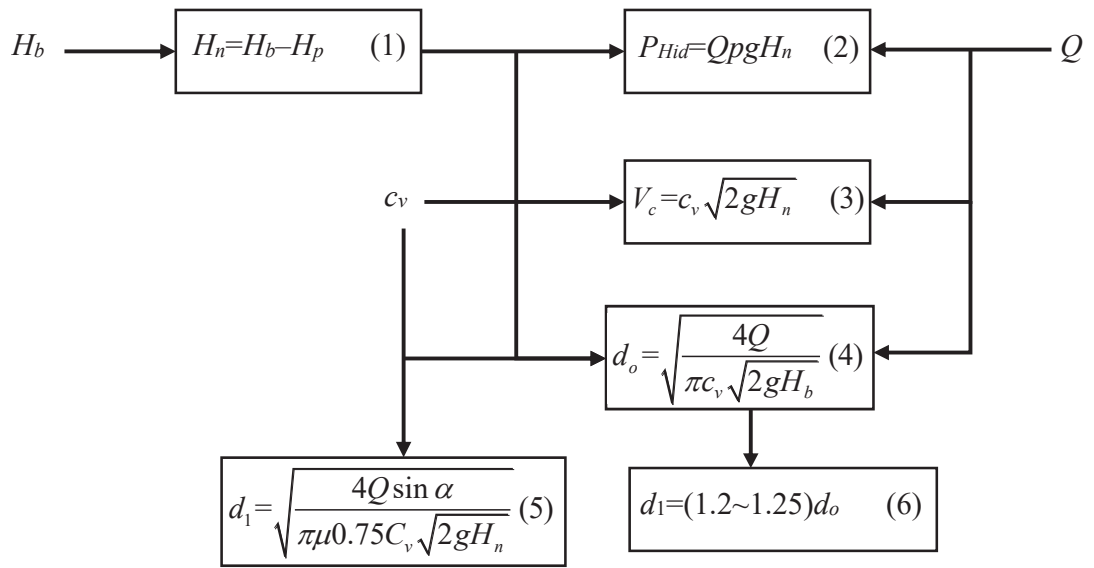

Fig. 1. Nozzle diameter and jet calculation process

Table 1

Obtaining the dimensions of the injector [26]

\section{Nomenclature}

C

$X$

$S$

$d$

I

$r$

$R$

$h$

e

$f$

\section{Correlation}

$0.63 d_{1}$

$0.503 d_{1}$

$1.35 d_{1}$

$0.63 d_{1}$

$3.17 d_{1}$

$0.705 d_{1}$

$2.2 d_{1}$

$0.6 d_{1}$

$0.05 d_{1}$

$1.13 d_{1}$

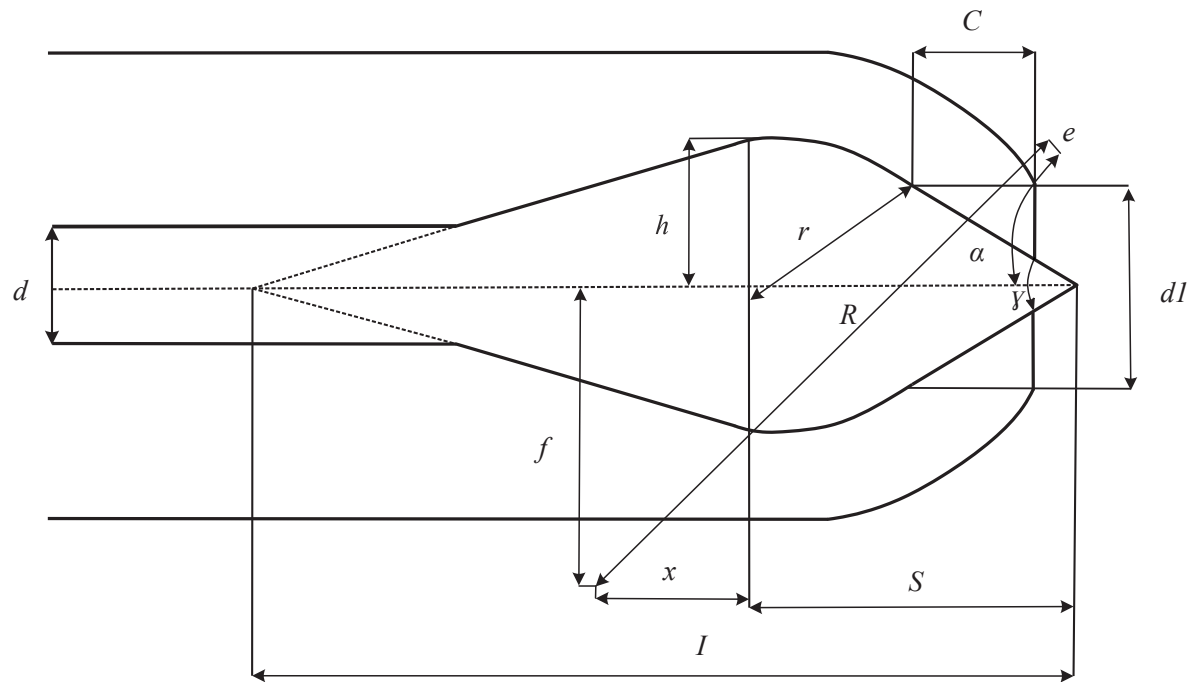

Fig. 2. Dimensions of the injector [26]

Table 1 and Fig. 2 show the nomenclature for obtaining the injector geometry and model. In addition, the dimensions correlate with the injector nozzle diameter in order to obtain the injector model for each selected needle tip angle $\left(55^{\circ}, 60^{\circ}\right.$ and $\left.75^{\circ}\right)$. 


\section{2. Control volume and boundary conditions}

Based on the geometries obtained in the design stage and using the SPACECLAIM ${ }^{\circledR}$ module of the ANSYS WORKBENCH program, control volumes were obtained corresponding to the volume of water flow contained inside the injector and the volume of air flow, as shown schematically in Fig. 3.

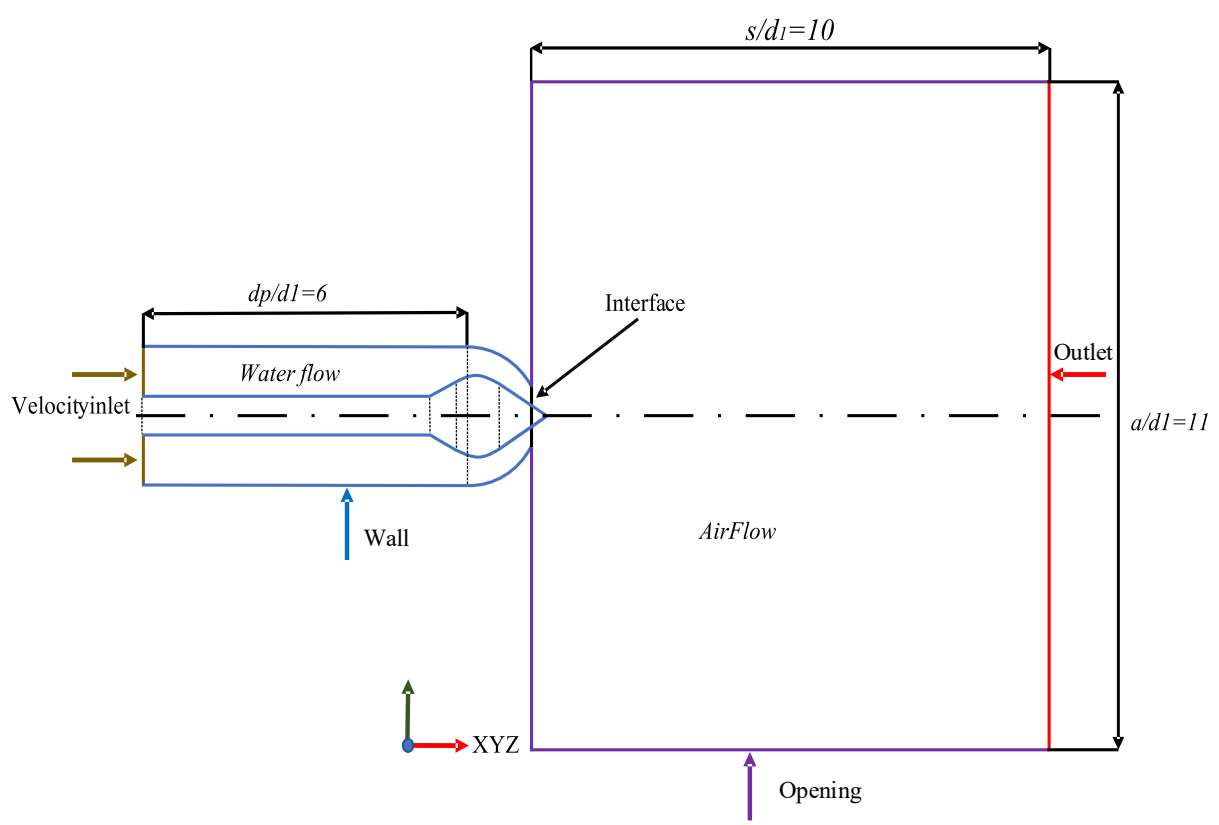

Fig. 3. Control volume and boundary conditions of the injector

For the configuration of the numerical model, the boundary conditions representing the physics of the problem were established. For this, a water-air interaction interface, a normal speed to the surface of $4,779 \mathrm{~m} / \mathrm{s}$ at the input, and an atmospheric boundary condition $(0 \mathrm{kPa})$ in the outlet was configured. Then, in order to establish and capture adequately the air currents induced by the action of the water jet, opening conditions were defined at the outlet of the nozzle. Finally, stationary walls were configured with a roughness of 0.03 and the boundary conditions for a volume fraction for gradients from 0 (air) to 1 (water) for the boundary conditions.

\section{3. Mesh generation}

The control volume discretization process was performed in the commercial ANSYS V20R1 software in the ICEM module. There, a structured mesh with hexahedral elements was implemented through the association of blocks and curves that compose the geometry of the control volume, as shown in Fig. 4, $\boldsymbol{a}$.

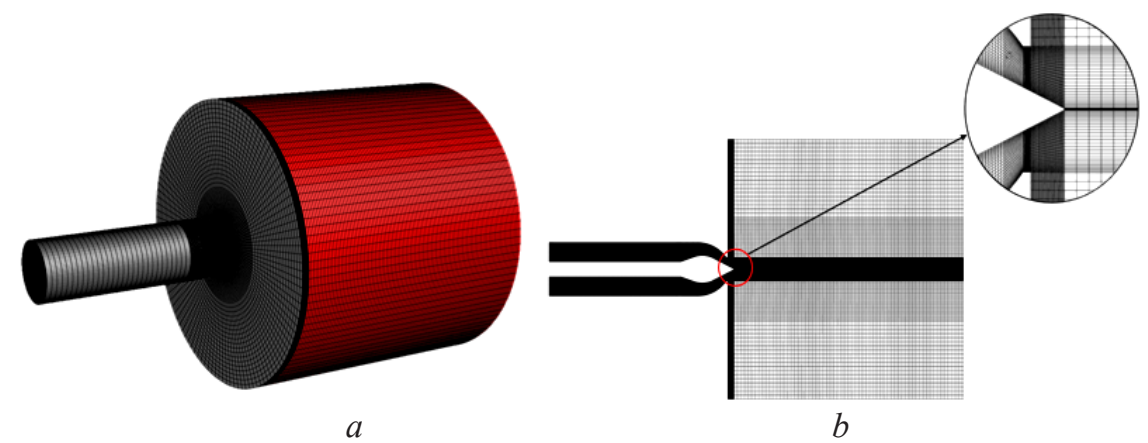

Fig. 4. Distribution mesh:

$a$-Isometric distribution mesh; $b$-Distribution plane $X Y$, refinement of the mesh 
Additionally, inflation was performed close to the walls of the needle and nozzle from a minimum required wall in order to adequately capture the hydrodynamic profile of the fluid as it interacts with the injector needle as shown in Fig. 4, b. For this, it was calculated the value of $y_{1}$ (height of the first cell), using a line tool as «Pointwise» [27]. Here, it was specified the velocity, density, dynamic viscosity and the diameter of the injector pipe for a $30<y^{+}<80$, obtaining a resolution close to the wall of $4 \mathrm{~mm}$ [15].

Table 2 presents the results obtained in the mesh metrics for each configured case of the injector in which it is validated that the quality of the mesh meets the necessary criteria for the simulation in ANSYS FLUENT, according to the parameters shown in the ANSYS working guides [28].

Table 2

Meshing metrics for injector needle geometries with $55^{\circ}, 60^{\circ}, 75^{\circ}$ tip angle

\begin{tabular}{|c|c|c|c|c|c|}
\hline \multirow{2}{*}{$\begin{array}{l}\text { Needle } \\
\text { tip angle }\end{array}$} & \multirow{2}{*}{ Mesh } & \multicolumn{4}{|c|}{ Recommend by [28] } \\
\hline & & Quality [>0.15] & Aspect relation $[<25]$ & Angle (Deg) $\left[>18^{\circ}\right]$ & Determinant $2 \times 2 \times 2[>15]$ \\
\hline \multirow{3}{*}{$55^{\circ}$} & Mesh 1 & 0.206 & 20 & 35.37 & 0.206 \\
\hline & Mesh 2 & 0.352 & 20 & 35.37 & 0.352 \\
\hline & Mesh 3 & 0.321 & 20 & 35.37 & 0.321 \\
\hline \multirow{3}{*}{$60^{\circ}$} & Mesh 1 & 0.215 & 20 & 35.37 & 0.215 \\
\hline & Mesh 2 & 0.285 & 13 & 35.37 & 0.285 \\
\hline & Mesh 3 & 0.329 & 17 & 35.37 & 0.329 \\
\hline \multirow{3}{*}{$75^{\circ}$} & Mesh 1 & 0.219 & 20 & 35.37 & 0.219 \\
\hline & Mesh 2 & 0.278 & 18 & 35.37 & 0.278 \\
\hline & Mesh 3 & 0.342 & 20 & 35.37 & 0.342 \\
\hline
\end{tabular}

In order to decrease the numerical error associated with the control volume discretization process, a mesh independence analysis was performed in response to the maximum water jet velocity as shown in Table 3 and Fig. 5.

Furthermore, it is possible to infer that the variable of interest (velocity) does not suffer significant changes higher than $2 \%$, that is, the simulations with $2.06 \times 106\left(55^{\circ}\right.$ needle), $3.14 \times 106\left(60^{\circ}\right.$ Techydro needle) and $2.73 \times 106\left(75^{\circ}\right.$ needle) are suitable to follow the simulation process, without consuming too many computational resources.

Table 3

Mesh Independence

\begin{tabular}{|c|c|c|c|c|c|}
\hline Needle tip angle & Simulations & Elements number & Nodes number & Maximum velocity $[\mathrm{m} / \mathrm{s}]$ & \%Error \\
\hline \multirow{3}{*}{$55^{\circ}$} & Simulation 1 & 1.776 .445 & 1.738 .012 & 33,47 & $0 \%$ \\
\hline & Simulation 2 & 2.068 .591 & 2.027 .692 & 34,28 & $2 \%$ \\
\hline & Simulation 3 & 2.643 .893 & 2.596 .412 & 34,73 & $4 \%$ \\
\hline \multirow{3}{*}{$60^{\circ}$} & Simulation 1 & 1.927 .341 & 1.891 .248 & 34.95 & $0 \%$ \\
\hline & Simulation 2 & 2.449 .921 & 2.408 .608 & 35.48 & $2 \%$ \\
\hline & Simulation 3 & 3.148 .241 & 3.099 .968 & 36.34 & $3 \%$ \\
\hline \multirow{3}{*}{$75^{\circ}$} & Simulation 1 & 2.003 .911 & 1.966 .648 & 46.6 & $0 \%$ \\
\hline & Simulation 2 & 2.739 .351 & 2.695 .128 & 48.1 & $2 \%$ \\
\hline & Simulation 3 & 3.521 .191 & 3.470 .008 & 45.5 & $4 \%$ \\
\hline
\end{tabular}




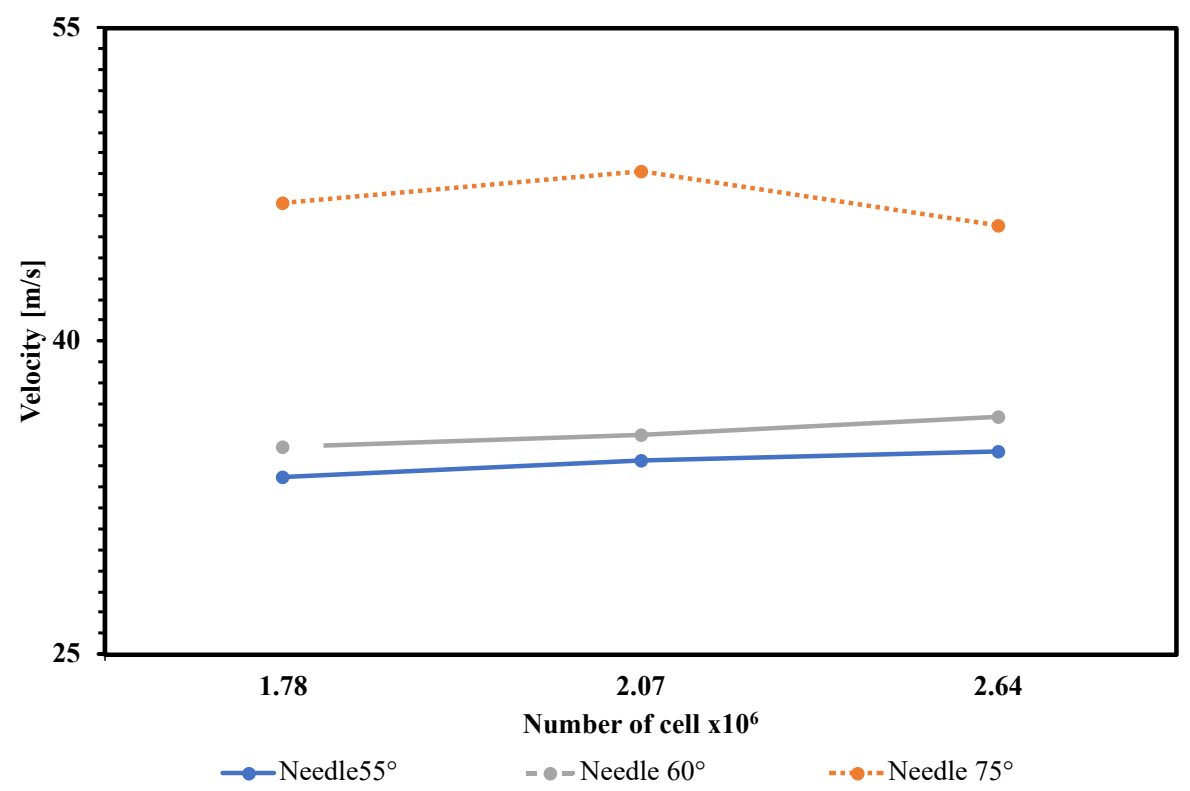

Fig. 5. Mesh Independence distribution

\section{4. Numerical Method}

A computational analysis was performed using ANSYS FLUENT V2020R1 from the approximations established by the Navier Stokes equations and the continuity, momentum and energy equations. The flow of the water jet has multiphase characteristics in a Pelton turbine which allows predicting the interaction between two immiscible fluids on a free surface, in which the position of the phase-to-phase interface is of interest for transient monitoring. Therefore, a multiphase VOF (volume of fluid) model was configure water and air at $25{ }^{\circ} \mathrm{C}$ and a constant surface tension of $0.072 \mathrm{~N} / \mathrm{m}$. In addition, the governing equations throughout the domain which depend on the volume fractions of all phases across the properties $\rho$ and $\mu$ as shown below $[4,29]$ :

$$
\begin{gathered}
\rho=\sum \alpha_{i} \rho_{i}, \\
\mu=\sum \alpha_{i} \mu_{i}, \\
\frac{\partial \rho}{\partial t}+\frac{\partial \rho \mu_{i}}{\partial x_{i}}=0, \\
\frac{\partial \alpha_{w}}{\partial t}-u_{i} \frac{\partial \alpha_{w}}{\partial x_{i}}=0, \\
\frac{\partial}{\partial t}\left(\rho \mu_{i}\right)+\frac{\partial}{\partial x_{i}}\left(\rho \mu_{i} \mu_{j}\right)=-\frac{\partial p}{\partial x_{i}}+\frac{\partial}{\partial x_{j}}\left[\mu\left(\frac{\partial \mu_{i}}{\partial x_{j}}+\frac{\partial \mu_{j}}{\partial x_{i}}-\frac{2}{3} \delta_{i j} \frac{\partial \mu_{l}}{\partial x_{l}}\right)\right]+\frac{\partial}{\partial x_{j}}\left(-\rho \overline{\mu_{i}^{\prime} \mu_{j}^{\prime}}\right) .
\end{gathered}
$$

The $k-\varepsilon$ turbulence model was selected for the study due to its good ability to correctly capture the viscous effects on the injector needle tip boundary layer and the free surface of the water jet, with low computational cost. The equations that govern the model are shown below [30, 31]:

$$
\begin{gathered}
\frac{\partial(\rho \bar{\mu} k)}{\partial x}+\frac{\partial(\rho \bar{v} k)}{\partial y}=\frac{\partial}{\partial x}\left[\left(\mu+\frac{\mu_{t}}{\sigma_{k}}\right) \frac{\partial k}{\partial x}\right]+\frac{\partial}{\partial y}\left[\left(\mu+\frac{\mu_{t}}{\sigma_{k}}\right) \frac{\partial k}{\partial y}\right]+P_{k}+G_{k}-\rho \varepsilon-Y_{M}, \\
\frac{\partial(\rho \bar{\mu} \varepsilon)}{\partial x}+\frac{\partial(\rho \overline{v \varepsilon})}{\partial y}=\frac{\partial}{\partial x}\left[\left(\mu+\frac{\mu_{t}}{\sigma_{\varepsilon}}\right) \frac{\partial \varepsilon}{\partial \varepsilon}\right]+\frac{\partial}{\partial y}\left[\left(\mu+\frac{\mu_{t}}{\sigma_{\varepsilon}}\right) \frac{\partial \varepsilon}{\partial y}\right]+\rho C_{1}-\rho C_{2 \varepsilon} \frac{\varepsilon^{2}}{k+\sqrt{v \varepsilon}}+C_{1 \varepsilon} \frac{\varepsilon}{k} C_{3 \varepsilon} G_{b} .
\end{gathered}
$$


Subsequently, the simulation was performed in a transient state in order to observe the behavior of the jet surface through time. Then, a total simulation time of $100 \mathrm{~s}$ was configured assuming a Courant-Friedrichs-Lewy (CFL) of 0.5 and an adaptive time step according to the cell size as shown in Table 4.

$$
C F L=\frac{V \Delta t}{\Delta x}<1
$$

This was calculated by (14), where $\Delta x$ is the distance from the cell in $[m], \Delta t$ is the time step in $[s]$ and $[V]$ is the velocity of the fluid in $[\mathrm{m} / \mathrm{s}]$ where it required a simulation time of approximately 36 hours for each case and an approximate duration of 324 hours, for the entire study. For this, it used a computer that has an Intel Xeon Es-2680 operating system with 16 logical processors and a RAM of $256 \mathrm{~Gb}$. Finally, as a stop criterion for each simulation case, a minimum residual value of 4x10-4 was established and a fluid velocity monitor at the nozzle outlet was monitored and controlled in order to verify a stable response.

Table 4

Time step Adaptive configuration in each case

\begin{tabular}{cccc}
\hline Needle tip angle & CFL & Cell's size $\left[\mathbf{m} \cdot \mathbf{1 0}^{-\mathbf{5}}\right]$ & ${\text { Time Step }\left[\mathbf{s} \cdot \mathbf{1 0} \mathbf{1 0}^{\mathbf{6}}\right]}$ \\
\hline $55^{\circ}$ & 0.5 & 4.11 & 4.30 \\
$60^{\circ}$ & 0.5 & 3.47 & 3.63 \\
$75^{\circ}$ & 0.5 & 3.64 & 7.62
\end{tabular}

\section{Results}

\section{1. Geometry results}

As a result of the design and modeling process of the injectors, three CAD models were obtained in commercial software ANSYS V20R1 in the «SPACECLAIM» module for $100 \%$ opening, one of which corresponds to the commercial model of the Techydro brand with a $60^{\circ}$ needle tip angle and two from the design equations described in the methodology.

Fig. 6 show the needle tip angle variation where the black color with continue line indicate the needle tip angle for $55^{\circ}$, the blue color with dash line for $60^{\circ}$ and red color with round dot for $75^{\circ}$.

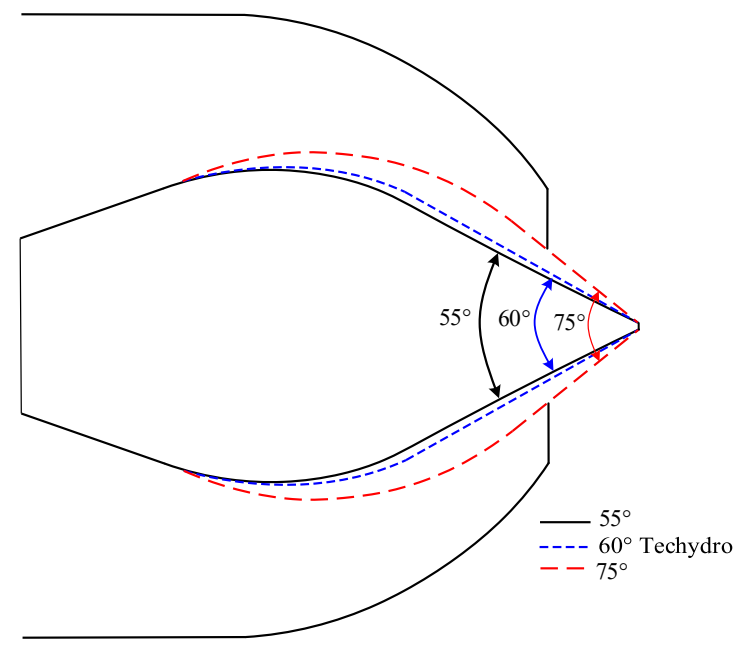

Fig. 6. Needle tip angle variation

\section{2. Discussion of simulation results}

The results are shown in a longitudinal reference plane and 3 transverse reference planes located in a normalized distance $\left(s / d_{1}\right)$, of $0.29,0.74,1.23,5.61$ and 10 at the nozzle exit where «(s)» corresponds to the distance between the nozzle and the reference plane and $d_{1}$ to the nozzle diameter (Fig. 7). 


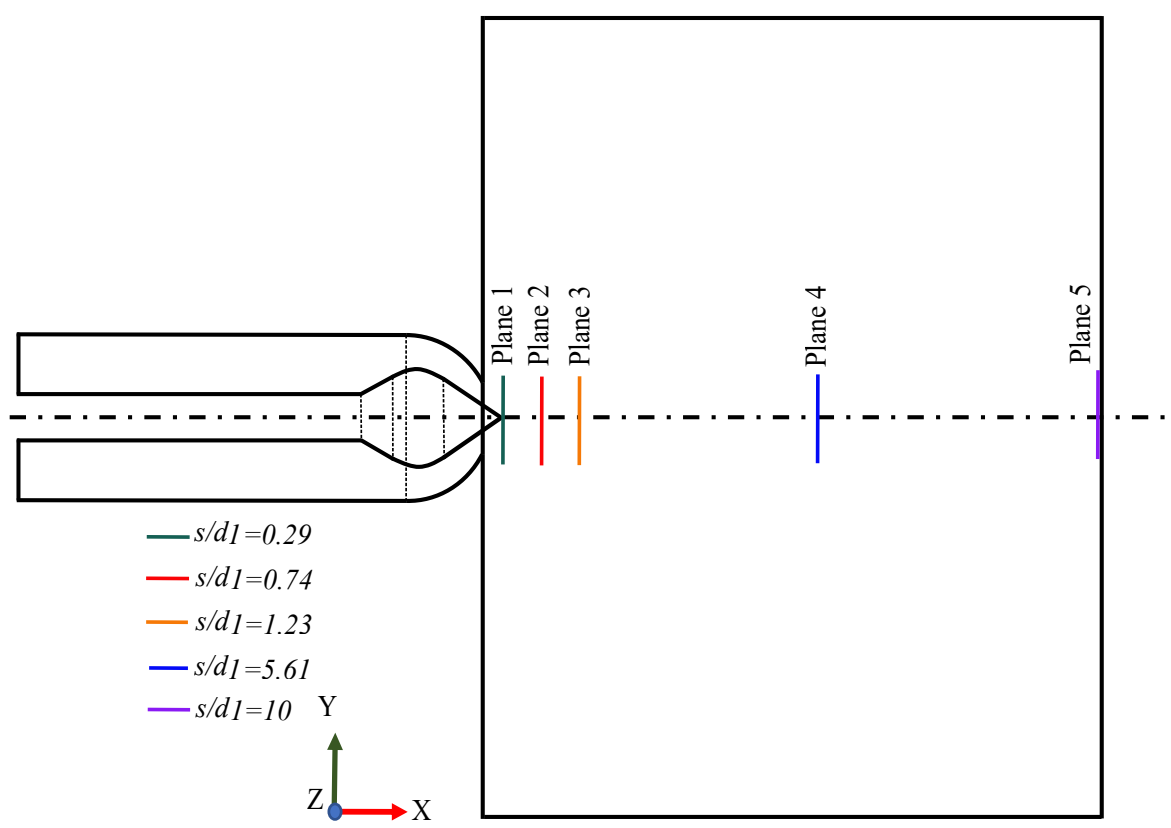

Fig. 7. Transversal and longitudinal reference planes

Additionally, it is possible to see the plane in Fig. 7 with colored lines indicating the position in which the results were taken where the red color indicated a normalized distance same to 0.29 , green line same to 0.74 , orange line same to 1.23 , blue line same to 5.61 and finally purple line same to 10 .

\section{2. 1. Jet characteristics}

Fig. 8 presents the volumetric fraction contours from the planes described in Fig. 7 for each design $\left(55^{\circ}, 60^{\circ}\right.$ Techydro and $\left.75^{\circ}\right)$.

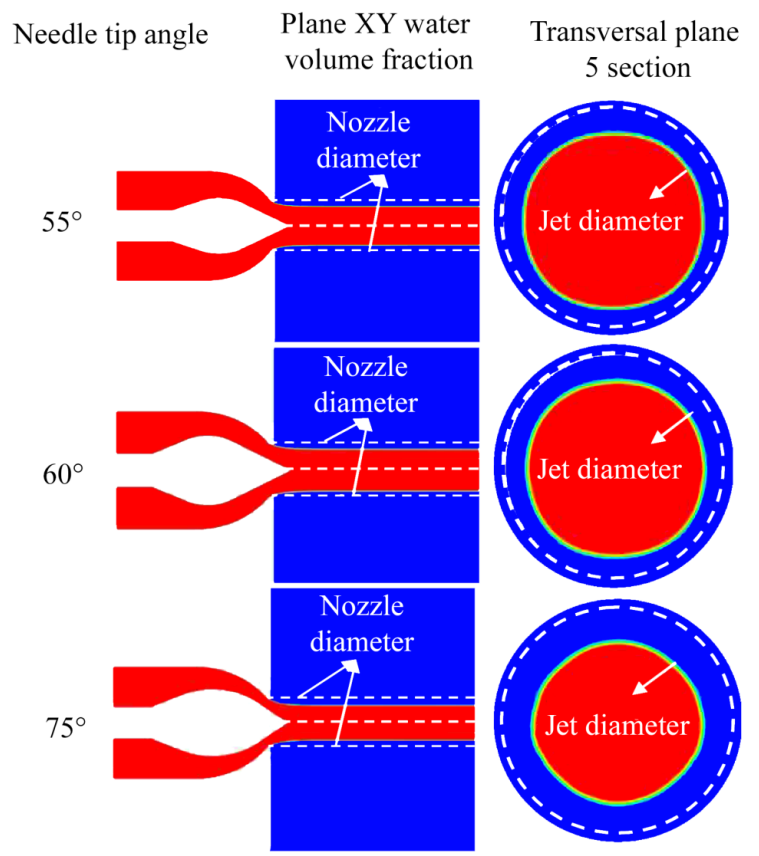

Fig. 8. Water volume fraction for each case

The volume fraction of water allowed the prediction and monitoring of the water-air jet interface where a value of $\alpha_{w}=1$ represents the volume fraction of a cell occupied by water 
while $\alpha_{w}=0$ indicates a cell occupied by air (10). Furthermore, white dotted lines corresponding to the nozzle diameter and $0 \%$ eccentricity described by [32] are presented, observing a minimum jet contraction and transversal deformations as a result of secondaries currents on its surface [33], resulting in standardized jet diameters $\left(d_{O C F D} / d_{O T H}\right)$ of $0.94,0.85$ and 0.76 for the needle tip angles of $55^{\circ}, 60^{\circ}$ and $75^{\circ}$ respectively. This means that the smaller the jet diameter, the higher the velocity and efficiency.

Fig. 9 presents the profile of the water fluid volume with respect to the diameter of the jet for each case of injector $\left(55^{\circ}, 60^{\circ}\right.$ and $\left.75^{\circ}\right)$. The Fig. shows slight changes in the jet diameter as the normalized distance s/d1 specified in planes 3, 4 and 5 of Fig. 5 is increased. Here, a symmetrical dispersion of the jet along its trajectory can be visualized, especially for the proposed needle angles $\left(55^{\circ}\right.$ and $\left.75^{\circ}\right)$. This is caused by the conservation of the mass and loss of energy in the jet, resulting in an increase in the jet's cross-sectional area and a conservation of the flow along its trajectory. However, in the commercial injector a jet dispersion is observed once it exceeds 0.5 of the fluid volumes for the three normalized distances mentioned due to the deformations that occur on the surface of the jet during its trajectory to the turbine buckets.

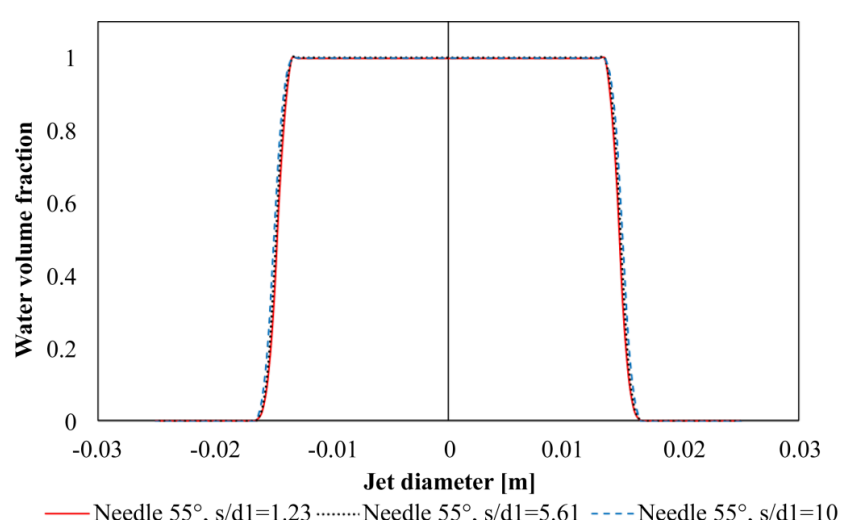

$a$

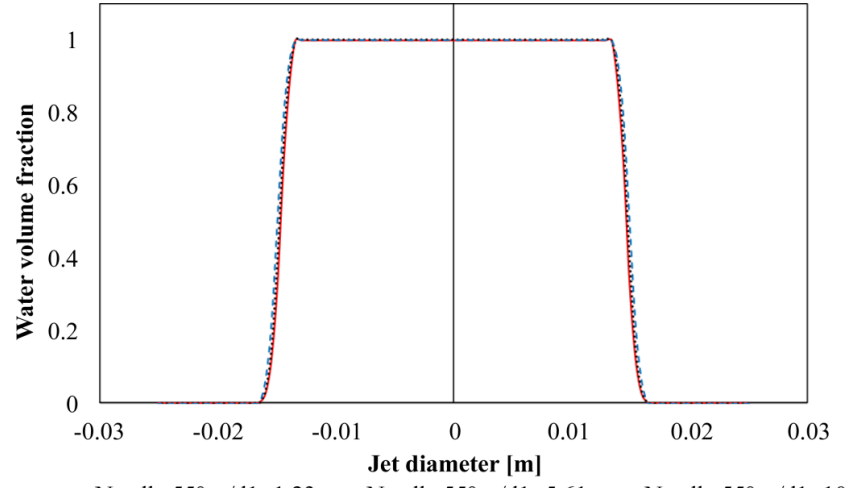

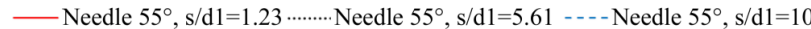

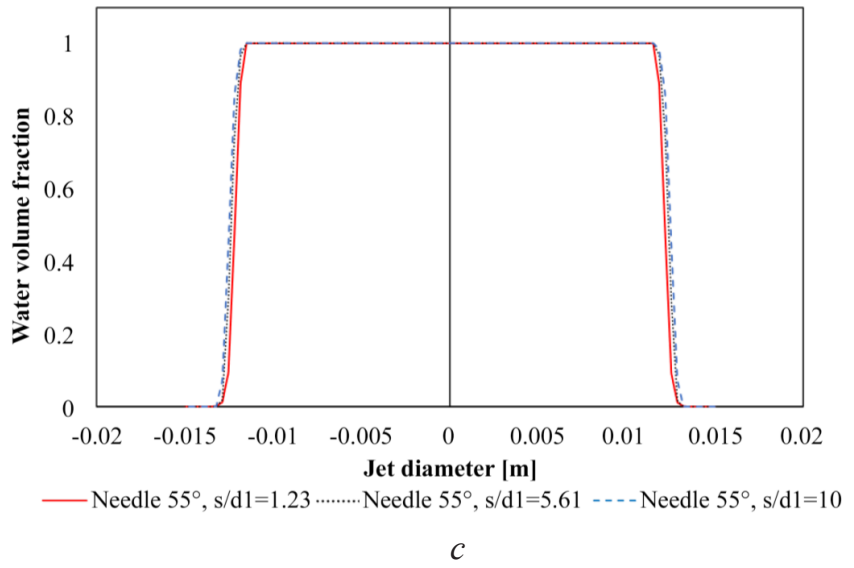

Fig. 9. Jet diameter for water volume fraction: $a$ - Needle $55^{\circ} ; b-$ Needle $60^{\circ} ; c-$ Needle $75^{\circ}$

Fig. 10 shows the velocity contours for the injector of $a-55^{\circ}, b-60^{\circ}$ and $c-75^{\circ}$. It is possible to observe maximum velocity in the jet of $33.5 \mathrm{~m} / \mathrm{s}, 35.5 \mathrm{~m} / \mathrm{s}$ and $48.1 \mathrm{~m} / \mathrm{s}$ for $55^{\circ}$, $60^{\circ}$ and $75^{\circ}$ needle tip angles respectively, which also decrease at the edge of the jet and at the core of the jet. This indicates, obtaining higher velocities for slightly more pronounced angles as observed in the study conducted by [15]. There, the increasing the angle of the needle and nozzle reduces the length of fluid interaction on them, reduces losses and increases the uniformity of the water jet which more beneficial for the performance of the turbine. Additionally, the cases show that the water jet is not totally uniform in its core because it has not reached its maximum velocity. 


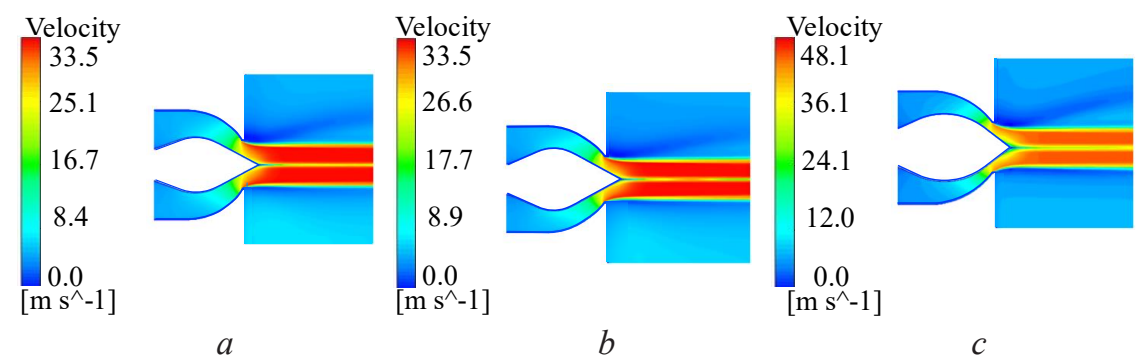

Fig. 10. Velocity contour distribution: $a$ - Needle $55^{\circ} ; b-$ Needle $60^{\circ}$ Techydro; $c-$ Needle $75^{\circ}$

Fig. 11 shows the velocity profile in different positions of the water jet for the cases $s / d 0.29 ; 0.74$ and 1.23 . The curves present lower velocities in the core of the jet, especially for the needle tip angle of $60^{\circ} / 130^{\circ}$ where the velocity in the core is almost zero for a normalized distance of 0.29 . This indicates that the distribution of the jet is not completely uniform in the core because the curvature presented has not reached its maximum value of velocity, and therefore it is still in the process of acceleration as presented in the experimental study conducted by [7]. Furthermore, according to the study provided by [16]. They indicated that the steeper angles in the injector needle present greater efficiency and better conditions in the operation of the turbine.

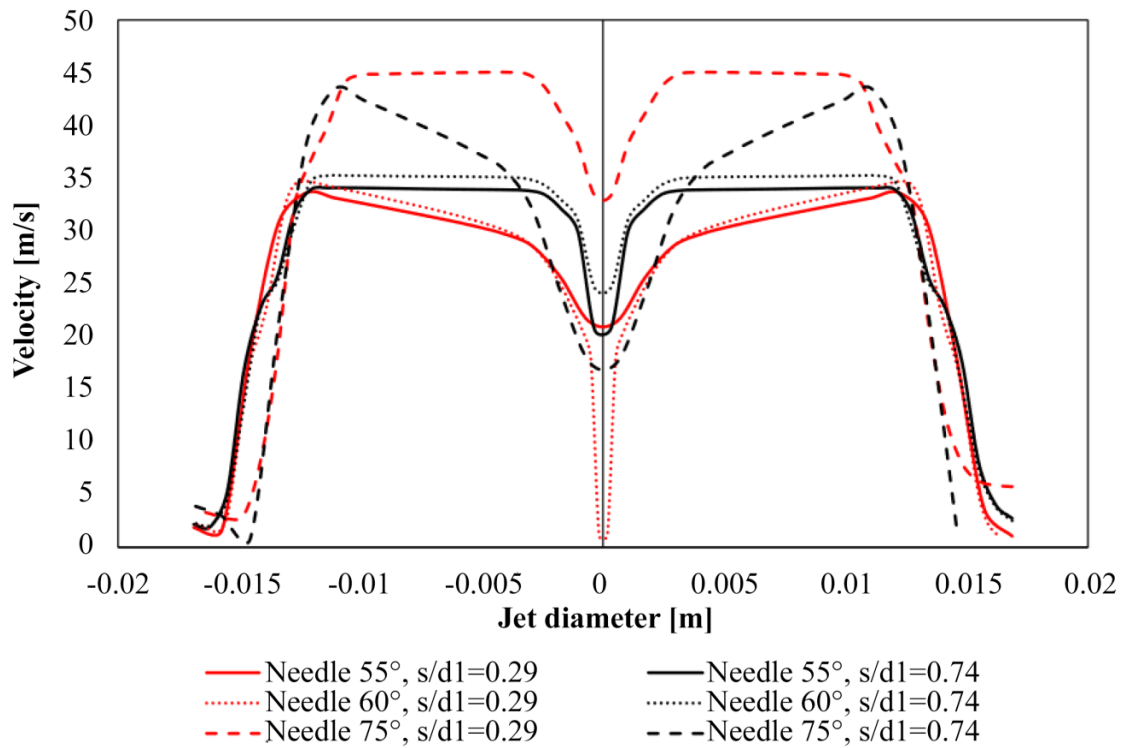

Fig. 11. Injector velocity profile for $55^{\circ}, 60^{\circ}$ Techydro and $75^{\circ}$

Fig. 12 shows the velocity profile in different positions of the water jet for the cases $\mathrm{s} / d_{1}$ of $1.23,5.61$ and 10 respect to $Y$ axis. It is possible to perceive a reduction of the velocity in the core of the water jet, especially for a normalized longitudinal distance $\left(s / d_{1}\right)$ of 1.23 for $55^{\circ}$, $60^{\circ}$ and $75^{\circ}$. This indicates that the jet has not yet achieved its maximum velocity and is therefore in the process of accelerating. In addition, a non-symmetrical divergence of the jet velocity profile can be observed as $s / d_{1}$ increases, because the effect of secondary currents increases the velocity of the fluid at those points, generating bucket imbalances that affect the power of the turbine.

In contrast, Fig. 12, 13 show a symmetrical increase in velocity at the edge of the jet, generating a balance that positively affects the impact of the jet on the bucket with respect to the $Z$-axis. Additionally, it is possible to observe a symmetry in the jet core for all three cases, obtaining jets more uniform in $Z$ axis. On the other hand, as in Fig. 12, velocities of approximately $6 \mathrm{~m} / \mathrm{s}$ are observed at the edge of the jet as a result of the increased velocity of the secondary currents in the 
jet. For this reason, although the more pronounced angles provide more uniform velocities, they also provide higher currents on its surface, causing deformations and dispersions that can affect the quality and efficiency of the turbine, as presented in the study by [34].

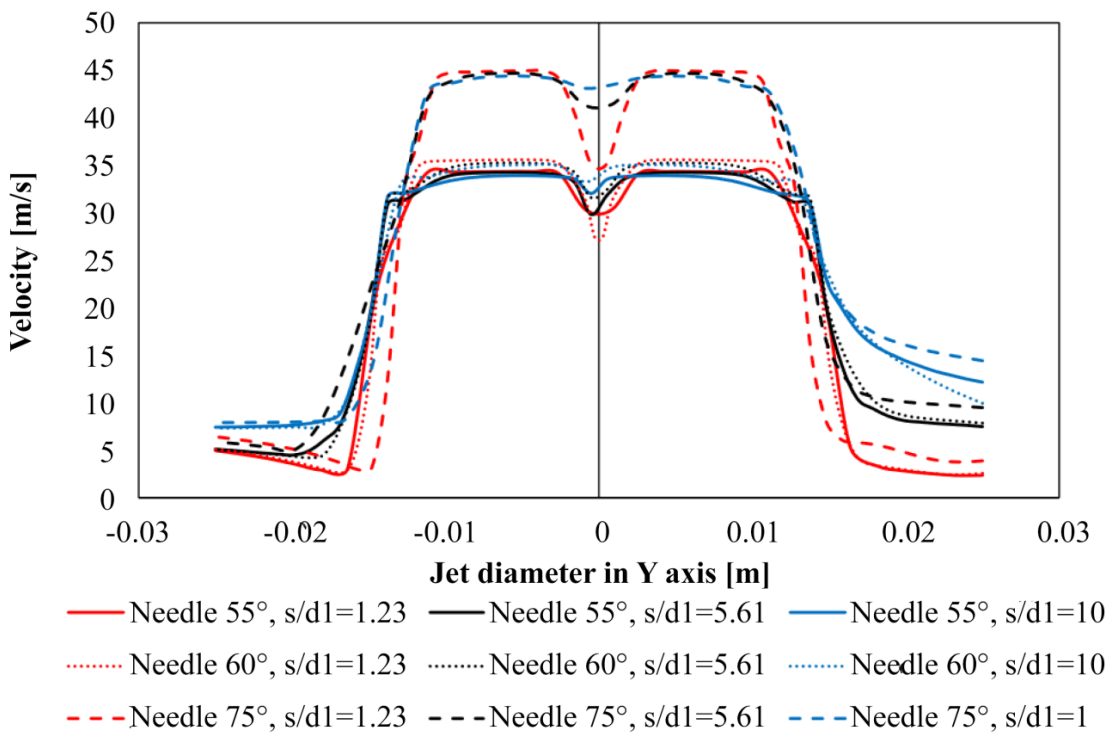

Fig. 12. Injector velocity profile for $55^{\circ}, 60^{\circ}$ Techydro and $75^{\circ}$

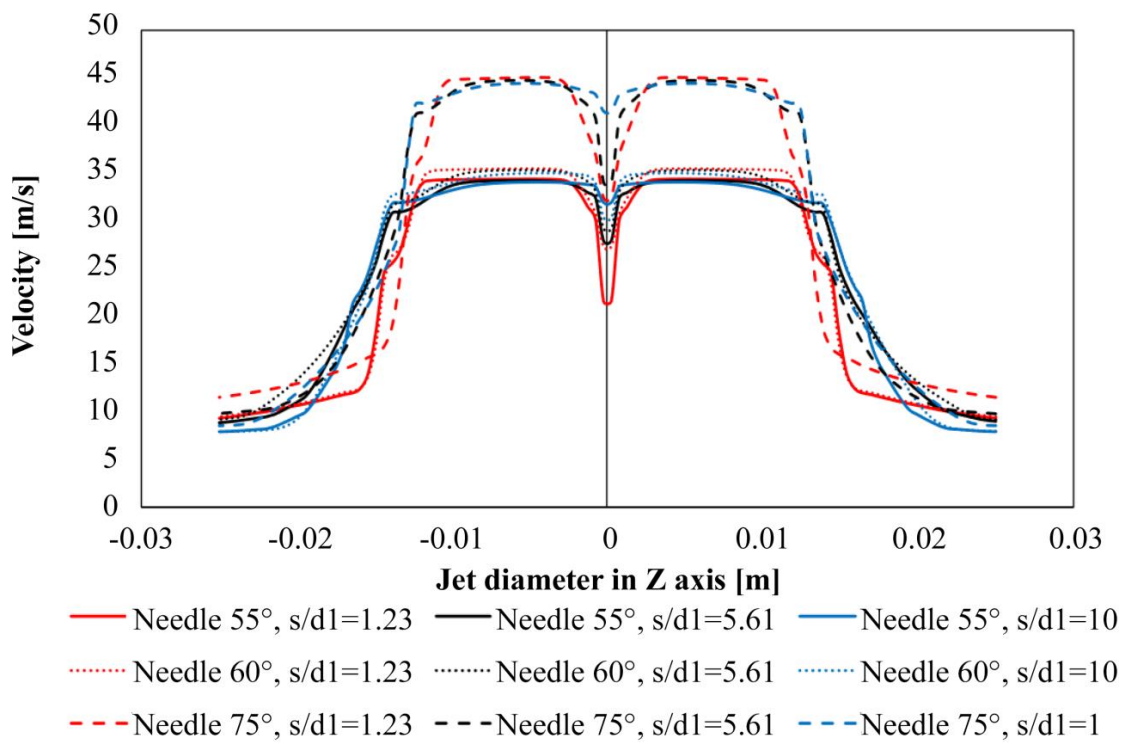

Fig. 13. Injector velocity profile in $Z$ axis for $55^{\circ}, 60^{\circ}$ Techydro and $75^{\circ}$

\section{2. 2. Secondary currents}

The Secondary currents are formed mainly by the interaction of the flow with respect to the elements inside the injector, producing small Dean's vortices that move towards the free surface of the jet, significantly affecting the quality of the jet around deformations and dispersions on its surface. Because of this, secondary currents have been the subject of study in recent years in order to improve the quality of the jets in the performance of the turbine. This is the case of [7] and [32] who by means of experimental methods of visualization and measurement LDA (Laser Doppler Anemometry) or computational CFD methods observed the dispersions and deformations of the jets produced by the secondary currents and the release of water drops in their trajectory. 
Fig. 14 shows the secondary currents traced in several transversal sections at normalized distances of $s / d_{1}$ of $1.23,5.61$ and 10 for each case $\left(55^{\circ}, 60^{\circ}\right.$ Techydro and $\left.75^{\circ}\right)$, which location is shown in Fig. 7.

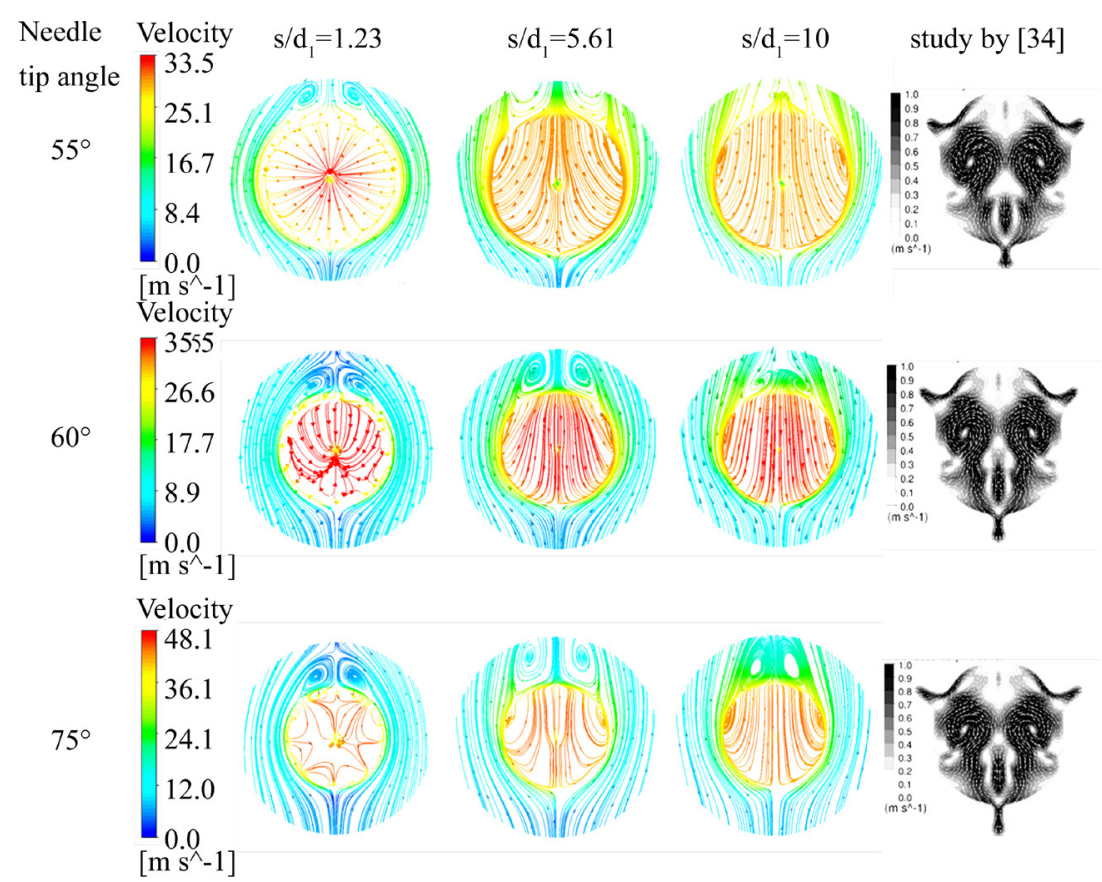

Fig. 14. Secondary current in the jet

The results show some disturbances caused by the Dean vortices due to the union of two currents that create stagnation zones at the top of the water jet that affect its quality. Consequently, since the jet is a free surface and does not have a retaining wall, the vortices increase the release of water drops that cause the dispersion and deformation of the jet, as shown in Fig. 8, 9. The first showed deformations in the jet transversal section for the three cases $\left(55^{\circ}, 60^{\circ}\right.$ Techydro and $\left.75^{\circ}\right)$ in the needle tip angle due to secondary currents escaping from its surface. The second showed that the velocity profiles are not completely uniform, and therefore have slight displacements in the core and the edge of the jet. On the other hand, these vortices cause the deflection of the jet and small irregularities that are observed in the upper part of the jet, where they grow significantly, especially for the $75^{\circ}$ angle (Fig. 14) where a complete detachment of the drop can produce. In contrast to the study carried out by [34], it can be seen that the more pronounced angles present higher secondary currents, resulting in the formation of a sequence of drops that increase the dispersion and deformation of the jet.

\section{2. 3. Injector efficiency}

Fig. 15 shows the efficiency of the injector $\left(55^{\circ}, 60^{\circ}\right.$ Techydro and $\left.75^{\circ}\right)$ from the volumetric flow rate normalized Q/QTH as a function of $\left(s / d_{1}\right)$.

Recent studies have estimated that the presence of more pronounced angles tends to increase the velocity of the water jet and consequently its efficiency [16]. Thus, results were compared with respect to two references in the literature [22,32] for $100 \%$ injector needle opening in relation to each configured case. The first shows an efficiency of $95.8 \%$ to $100 \%$ of opening, presenting a difference below $1 \%$ and $1.7 \%$ for the $55^{\circ}$ and $60^{\circ}$ injector respectively, and above $0.21 \%$ for the $75^{\circ}$ injector. The second shows an efficiency of $96.2 \%$, establishing a difference below $2.18 \%, 1.03 \%$ and $0.2 \%$ for $55^{\circ}, 60^{\circ}$ and $75^{\circ}$ respectively. Additionally, it is possible to observe an efficiency of $95.17 \%$ for the $60^{\circ}$ commercial injector which presents over $1.15 \%$ with respect to the proposed $55^{\circ}$ injector and an efficiency below $0.83 \%$ with respect to the $75^{\circ}$ injector. 


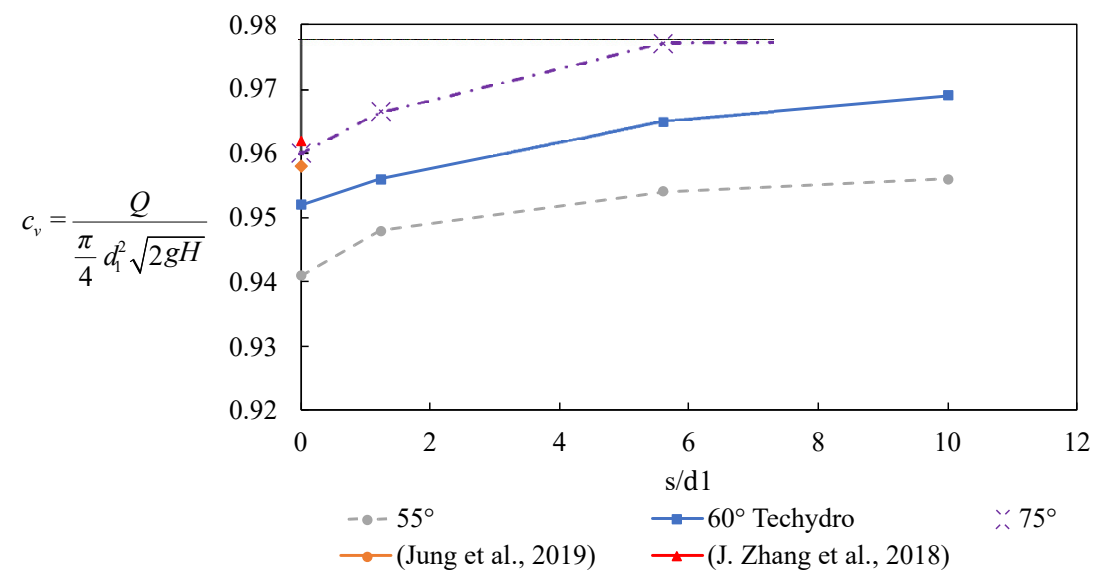

Fig. 15. Volumetric flow efficiency of the injector as a function of the normalized longitudinal distance of the nozzle diameter

On the other hand, it can be observed that in the three curves $\left(55^{\circ}, 60^{\circ}\right.$ and $\left.75^{\circ}\right)$ the efficiency increases in proportion to the increase in $s / d_{1}$. However, between the normalized distance $s / d_{1}$ of 5.61 and 10 the increase in efficiency is not very significant for the injector with needle tip angle of $55^{\circ}, 60^{\circ}$ and $75^{\circ}$, where its efficiency only increases by $0.2 \%, 0.4 \%$ and $0.02 \%$ respectively. This indicates that the area of the jet increases and the speed of the jet decreases gradually, obtaining a dispersion effect in the jet, as observed in Fig. 9.

\section{Conclusions}

The study presented and analyzed by means of CFD computational simulations the variation of the needle tip angle on the jet characteristics and the efficiency of the injector. This is based on a methodology developed through the generation of a commercial Techydro ${ }^{\circledR}$ geometric model with $60^{\circ}$ angle and two geometries designed with $55^{\circ}$ and $75^{\circ}$ angles at the needle tip. Also, they were analyzed using the multiphase VOF (volume of fluid) method and a turbulence model $k-\varepsilon$, obtaining computational results that affect the quality of the free surface of the water jet and the efficiency of the injector described in studies conducted by authors in the literature. Consequently, the discretization of the control volume influences the velocity simulation results according to the number of elements and nodes set. The efficiency and quality of the jets have a direct relationship with the variation in the injector needle tip angles. These angle configurations present Dean vortices that cause an increase in the deformation and dispersion of the water jet. the influence of the needle tip angle showed significant variations in efficiency, obtaining results of $96 \%$ for a $75^{\circ} / 110^{\circ}$ nozzle outlet configuration, showing a variation of $0.83 \%$ and $-1.23 \%$ in efficiency respectively to the commercial needle tip angle geometry of $55^{\circ} / 110^{\circ}$, respectively.

\section{Acknowledgments}

We would like to express our thanks to our colleagues from [Departament of Mechatronics and Electromechanics/Metropolitan Technological Institute] and [faculty of engineering/Pontifical Bolivarian University] who provided insight and expertise that greatly assisted the research.

\section{Reference}

[1] Statistical Review of World Energy, 2020 | 69th Edition. Available at: https:/www.bp.com/content/dam/bp/business-sites/en/ global/corporate/pdfs/energy-economics/statistical-review/bp-stats-review-2020-full-report.pdf

[2] Pelton, L. A. (1980). Pat. No. US233692A. Water Wheel. No. 233,692. Available at: https://patentimages.storage.googleapis. com/6a/19/4e/26608eb3abf576/US233692.pdf

[3] Nechleba, M. (1957). Hydraulic Turbines: Their design and equipment. Prague.

[4] Yin, Z., Shi, B., Zhang, T., Ma, J. (2009). The VOF Method Based on Refined Grids Partition of Partial Domain. Advances in Water Resources and Hydraulic Engineering, 1823-1828. doi: https://doi.org/10.1007/978-3-540-89465-0_314 
[5] Koukouvinis, P. K., Anagnostopoulos, J. S., Papantonis, D. E., Simos, T. E., Psihoyios, G., Tsitouras, C. (2009). Turbulence Modeling in Smoothed Particle Hydrodynamics Methodology: Application in Nozzle Flow. AIP Conference Proceedings. doi: https://doi.org/10.1063/1.3241439

[6] Zhang, Z., Parkinson, E. (2002). LDA application and the dual-measurement-method in experimental investigations of the free surface jet at a model nozzle of a Pelton turbine. Conference: 11th. International Symposium on Applications of Laser Anemometry to Fluid Mechanics.

[7] Zhang, Z., Casey, M. (2007). Experimental studies of the jet of a Pelton turbine. Proceedings of the Institution of Mechanical Engineers, Part A: Journal of Power and Energy, 221 (8), 1181-1192. doi: https://doi.org/10.1243/09576509jpe408

[8] List, B., Prost, J., Matthias, H. (2000). Using Piv on the Splash Water in a Pelton Turbine. XVI IMEKO World Congress. Vienna, 1-5.

[9] Zeng, C., Xiao, Y., Luo, Y., Zhang, J., Wang, Z., Fan, H., Ahn, S.-H. (2018). Hydraulic performance prediction of a prototype four-nozzle Pelton turbine by entire flow path simulation. Renewable Energy, 125, 270-282. doi: https://oi.org/10.1016/ j.renene.2018.02.075

[10] Chongji, Z., Yexiang, X., Wei, X., Tao, W., Jin, Z., Zhengwei, W., Yongyao, L. (2016). Numerical Analysis of Pelton Nozzle Jet Flow Behavior Considering Elbow Pipe. IOP Conference Series: Earth and Environmental Science, 49, 022005. doi: https:// doi.org/10.1088/1755-1315/49/2/022005

[11] Fiereder, R., Riemann, S., Schilling, R. (2010). Numerical and experimental investigation of the 3D free surface flow in a model Pelton turbine. IOP Conference Series: Earth and Environmental Science, 12, 012072. doi: https://oi.org/10.1088/ 1755-1315/12/1/012072

[12] Peron, M., Parkinson, E., Geppert, L., Staubli, T. (2008). Importance of jet quality on Pelton efficiency and cavitation. Int. Conf. on Hydraulic Efficiency Measurements, 1-9.

[13] Staubli, T. et. al. (2009). Jet quality and Pelton efficiency. Conference: Hydro 2009. Lyon.

[14] Staubli, T., Hauser, H. P. (2004). Flow visualization - a diagnosis tool for pelton turbines. IGHEM2004. Lucerne, 1-9.

[15] Benzon, D. S. (2016). The Turgo impulse turbine; a CFD based approach to the design improvement with experimental validation. Lancaster. Available at: https://eprints.lancs.ac.uk/id/eprint/82918/1/2016benzonphd.pdf

[16] Benzon, D., Židonis, A., Panagiotopoulos, A., Aggidis, G. A., Anagnostopoulos, J. S., Papantonis, D. E. (2015). Impulse Turbine Injector Design Improvement Using Computational Fluid Dynamics. Journal of Fluids Engineering, 137 (4). doi: https://doi.org/10.1115/1.4029310

[17] Petley, S., Panagiotopoulos, A., Benzon, D. S., Židonis, A., Aggidis, G. A., Anagnostopoulos, J. S., Papantonis, D. E. (2019). Investigating the influence of the jet from three nozzle and spear design configurations on Pelton runner performance by numerical simulation. IOP Conference Series: Earth and Environmental Science, 240, 022004. doi: https://doi.org/10.1088/ $1755-1315 / 240 / 2 / 022004$

[18] Thaung, Z. C. (2018). Experimental and Numerical Computational Fluid Dynamics Analysis on the Flow at Pelton Turbine Nozzle with Various Opening Settings. International Journal of Science and Engineering Applications, 7 (08), 169-174. Available at: https://ijsea.com/archive/volume7/issue8/IJSEA07081008.pdf

[19] Nesiadis, A. V., Papantonis, D. E., Anagnostopoulos, J. S. (2011). Numerical Study of the Effect of Spear Valve Design on the Free Jet Flow Characteristics in Impulse Hydroturbines. 7th GRACM International Congress on Computational Mechanics. Athens. Available at: https://www.researchgate.net/publication/281096055_NUMERICAL_STUDY_OF_THE_EFFECT_OF_ SPEAR_VALVE_DESIGN_ON_THE_FREE_JET_FLOW_CHARACTERISTICS_IN_IMPULSE_HYDROTURBINES

[20] Nesiadis, A. V., Anagnostopoulos, J. S., Papantonis, D. E. (2013). Study of the injector design in impulse hydro turbines. AIP Conference Proceedings. doi: https://doi.org/10.1063/1.4825999

[21] Jošt, D., Mežnar, P., Lipej, A. (2010). Numerical prediction of Pelton turbine efficiency. IOP Conference Series: Earth and Environmental Science, 12, 012080. doi: https://oi.org/10.1088/1755-1315/12/1/012080

[22] Zhang, J., Xiao, Y. X., Wang, J. Q., Zhou, X. J., Xia, M., Zeng, C. J. et. al. (2018). Optimal design of a pelton turbine nozzle via 3D numerical simulation. IOP Conference Series: Earth and Environmental Science, 163, 012066. doi: https:// doi.org/10.1088/1755-1315/163/1/012066

[23] Alnakhlani, M. M., Mukhtar, M., Himawanto, D. A., Alkurtehi, A., Danardono, D. (2014). Effect of the Bucket and Nozzle Dimension on the Performance of a Pelton Water Turbine. Modern Applied Science, 9 (1). doi: https://doi.org/10.5539/mas.v9n1p25

[24] Gass, M. (2002). Modification Of Nozzles For The Improvement Of Efficiency Of Pelton Type Turbines. HydroVision 2002, 1-7. Available at: http://hydromg.com/articles/mod\%20nozzle\%202002.pdf

[25] Unterberger, P., Bauer, C., Gaschl, J., Mack, R. (2010). Studies on the free jet of pelton nozzles. Conference: Reliable hydropower for a safe and sustainable power production. Available at: https://www.researchgate.net/publication/260508415 Studies_on_the_free_jet_of_pelton_nozzles 
[26] Theint, K., Myo, L. (2018). Design of Speed Control System for Pelton Turbine. International Journal of Scientific and Research Publications (IJSRP), 8 (7). doi: https://doi.org/10.29322/ijsrp.8.7.2018.p7950

[27] Pointwise. Y+ calculate. Available at: https://www.pointwise.com/yplus/index.html

[28] ANSYS ICEM CFD Tutorial Manual. Available at: https://engineering.purdue.edu/ scalo/menu/teaching/me608/tutorial.pdf

[29] Chongji, Z., Yexiang, X., Wei, Z., Yangyang, Y., Lei, C., Zhengwei, W. (2014). Pelton turbine Needle erosion prediction based on 3D three-phase flow simulation. IOP Conference Series: Earth and Environmental Science, 22 (5), 052019. doi: https:// doi.org/10.1088/1755-1315/22/5/052019

[30] Shih, T.-H., Liou, W. W., Shabbir, A., Yang, Z., Zhu, J. (1995). A new k- $€$ eddy viscosity model for high reynolds number turbulent flows. Computers \& Fluids, 24 (3), 227-238. doi: https://oi.org/10.1016/0045-7930(94)00032-t

[31] Bajracharya, T. R., Shrestha, R., Timilsina, A. B. (2019). A Methodology for Modelling of Steady State Flow in Pelton Turbine Injectors. Journal of the Institute of Engineering, 15 (2), 246-255. doi: https://doi.org/10.3126/jie.v15i2.27674

[32] Jung, I. H., Kim, Y. S., Shin, D. H., Chung, J. T., Shin, Y. (2019). Influence of spear needle eccentricity on jet quality in micro Pelton turbine for power generation. Energy, 175, 58-65. doi: https://doi.org/10.1016/j.energy.2019.03.077

[33] Staubli, T., Abgottspon, A., Weibel, P., Bissel, C., Parkinson, E., Leduc, J. (2009). Die Auswirkung der Strahlqualität auf den Wirkungsgrad von Peltonturbinen. Wasser Energ. Luft, 101 (3), 181-188.

[34] Petley, S., Židonis, A., Panagiotopoulos, A., Benzon, D., Aggidis, G. A., Anagnostopoulos, J. S., Papantonis, D. E. (2019). Out With the Old, in With the New: Pelton Hydro Turbine Performance Influence Utilizing Three Different Injector Geometries. Journal of Fluids Engineering, 141 (8). doi: https://doi.org/10.1115/1.4042371

Received date 17.03.2021

Accepted date 20.04.2021

Published date 31.05.2021
(C) The Author(s) 2021

This is an open access article under the Creative Commons CC BY license

How to cite: Taborda, D. G., Rio, J. S.-D., Perez-Alvarez, J. D., Cardona-Vargas, A., Villa, D. S. (2021). CFD analysis of the needle tip angle in Pelton injector on jet quality for the power generation. EUREKA: Physics and Engineering, 3, 45-59. doi: https://doi.org/10.21303/2461-4262.2021.001828 